\title{
HUBUNGAN PERAWATAN CATHETER VENA CENTRAL (CVC) TERHADAP TERJADINYA INFEKSI ALIRAN DARAH PRIMER (IADP)
}

\author{
Basri $^{1}$, Siti Nurhayati ${ }^{2}$ \\ ${ }^{1,2}$ Institut Kesehatan Sumatera Utara, Medan \\ Email: basririfki@gmail.com
}

\begin{abstract}
Central vein Catheter Treatment $(C V C)$ is the treatment of a hose that is used to provide liquids or medicines. Appliance is installed in a blood vessel near the heart. The primary infection of blood flow occurring within 48 hours after the installation of CVC The purpose of this research is to know the CVC treatment relationship in CVC attached patients to the primary blood flow infection in ICU RSUP. H. Adam Malik Medan. The study uses correlation and observation research methods. The population in this research is the entire patient who CVC has installed, as well as all the nurses who do the CVC treatment. Based on the data obtained by the patient as much as 76 people. Patients are inclusiveness if the patient is hospitalized in less than 24 hours, and drop out if the patient dies in the treatment before it is found signs of IADP, as well as patients who come out of Adam Malik, then there are 32 patients. Research instruments in the form of questionnaires according to IADP. Analysis of data used statistical tests test Chi-Square. The results of the majority of the study of a major vein catether treatment $(C V C)$ were as much as 28 (87.5\%), the majority of which did not occur as much as 27 people (84.4\%). Statistical test results obtained by the value of $p$-value $=0.000(<0.05)$ can be concluded there is a central venous catether treatment Relationship (CVC) in patients attached CVC to the occurrence of primary blood flow infection).
\end{abstract}

Keywords: CVC treatment, primary blood, flow infection

\section{PENDAHULUAN}

Ruang Perawatan Intensif merupakan bagian dari bangunan rumah sakit yang memiliki kategori pelayanan kritis, instalasi bedah dan instalasi gawat darurat. Ruang perawatan yang memiliki instalasi pelayanan khusus dengan menyediakan pelayanan secara komprehensif dan berkesinambungan selama 24 jam. Ruangan didukung oleh bangunan dan prasarana (utilitas) yang memenuhi persyaratan secara teknis sesuai standar yang berlaku (Kementerian Kesehatan RI, 2012).
Pasien yang dirawat di ruang perawatan kritis memiliki resiko yang tinggi terhadap kehidupannya. Mengingat banyaknya jumlah pemasangan Central vein Catheter (CVC) di ruang rawat intensif. Menurut Agarwal, Warner, Reichner, dan Lazarous (2014), akses intravena pada pasien critical ill membutuhkan waktu yang cukup lama. Kateter intravena berdiameter kecil yang bertempat di vena-vena perifer dapat berpotensi terjadi peradangan lokal 
dan terjadinya trombosis.

Salah satu komplikasi tersering akibat pemasangan CVC adalah infeksi aliran darah, yang dikenal sebagai Central Line Associated Bloodstream Infection (CLABSI) dan merupakan salah satu sumber infeksi terbesar dari rumah sakit. Menurut Centers for Disease Control and Prevention (2016), meskipun penurunan $46 \%$ dalam CLABSI telah terjadi di rumah sakit di seluruh AS dari 2008-2013, diperkirakan 30.100 infeksi aliran darah yang terkait dengan garis tengah (CLABSI) masih terjadi di unit perawatan intensif dan lingkungan dari fasilitas perawatan akut AS setiap tahun

Langkah pencegahan CLABSI dikembangkan oleh Institute for Healthcare Improvement menjadi suatu sistem yang disebut Central Line Bundle (CLB), yang terdiri dari tindakan pencegahan saat insersi dan pemeliharaan CVC. Implentasi CLB telah berhasil lebih dari $66 \%$ di 108 ruang rawat intensif dewasa menurunkan angka kejadian CLABSI di Michigan, Amerika Serikat.

Pemasangan alat tersebut perlu dilakukan pada pasien yang memerlukan akses vena atau pemberian obat-obatan yang harus dilakukan secara terus menerus, obat-obatan dengan konsentrasi tinggi (hight allert), pemberian parenteral nutrisi, obat- obatan kemoterapi, pengambilan sampel darah, pemberian donor darah, dan pasien yang memerlukan pemantauan hemodinamik melalui CVP (Central Venous Pressure) (Garber \& Puopolo, 2015).

Pasien yang berada di unit perawatan kritis seperti ruangan ICU memiliki resiko yang besar yang mengancam kehidupannya. Menurut Miller (2017), pasien-pasien critical care beresiko tinggi untuk mengalami gangguan kesehatan yang mengancam kehidupan baik aktual maupun potensial. Monitoring hemodinamik pada pasien dengan kondisi kritis di ruang rawat bertujuan mendeteksi gangguan insufisiensi kardiovaskuler, mengetahui faktor yang berkontribusi dan petunjuk untuk melakukan terapi selanjutnya.

Terdapat beberapa ruangan di RSUP H. Adam Malik Medan dimana sering pasien yang dirawat harus dilakukan pemasangan CVC antara lain Ruang HCU, Ruang ICU Dewasa, ICU Pasca Bedah, PICU, Ruang ULB, Ruang NICU, dan ruang operasi. Data PPI di rumah sakit tahun 2019 didapat jumlah rata-rata pasien terpasang alat tersebut di ruang ICU pada 3 bulan terakhir sebanyak 72 orang, dimana ruangan ICU sebanyak 45 orang, dan ruang rawat inap sebanyak 27 orang.

Berdasarkan data PPI tahun 2018 terdapat angka kejadian infeksi untuk 
kasus Infeksi Aliran Darah Primer (IADP) sendiri sebanyak 13 kasus dan sedangkan di 6 bulan terakhir di tahun 2019 terdapat 7 kasus. Penggunaan CVC berhubungan dengan infeksi pada aliran darah yang disebabkan oleh mikroorganisme yang berasal dari cairan ketika alat diinsersikan atau setelah insersi. Menurut Said, Taslim, dan Bahar (2016), keadaan luka insersi akan dipengaruhi oleh tingkat albumin serta asupan makanan.

Berdasarkan observasi peneliti pada status dan keadaan pasien di Instalasi Anastesiologi dan perawatan Intensive didapatkan data bahwa pasien yang di rawat merupakan pasien yang mengalami berbagai jenis penyakit primer atau skunder seperti gagal nafas, gagal ginjal, syok septik, gagal jantung, luka bakar, dimana rata-rata pasien menggunakan alat tersebut karena banyaknya terapi yang di berikan melalui vena. Hal ini dapat berdampak pada lamanya hari rawat.

Adapun upaya yang dilakukan untuk pencegahan IADP yaitu dengan menjalan kan bundle IADP yang telah diterbitkan oleh tim PPI rumah sakit. Berdasarkan dari studi pendahuluan yang peneliti lakukan di ruang ICU, maka peneliti tertarik untuk meneliti tentang hubungan perawatan CVC pada pasien terpasang CVC terhadap terjadinya infeksi aliran darah.

\section{METODE}

Penelitian ini menggunakan metode observasi. Dimana penelitian ini bertujuan untuk mengetahui hubungan perawatan CVC terhadap terjadinya infeksi aliran darah primer di ruangan intensive care unit.

Tempat penelitian ini di ruangan Intensive Care Unit (ICU) RSUP. H. Adam Malik Medan. Waktu penelitian ini dilakukan pada bulan Desember 2019 sampai dengan Januari 2020.

Populasi dalam penelitian ini adalah seluruh pasien yang terpasang CVC. Pemilihan sampel pada penelitian ini yaitu dengan accidental sampling. Dimana dari data pasien pasien 3 bulan terakhir rata-rata sebanyak 76 orang. Pasien diinklusikan bila pasien dirawat kurang dari 24 jam, dan drop out bila pasien meninggal dalam perawatan sebelum ditemukan adanya tanda tanda IADP atau pasien tidak dirawat. (pindah ke RS lain atau pulang paksa atau PAPS ), serta pasien yang terpasang alat di ruangan, sehingga didapat jumlah sampel sebanyak 32 orang.

Persiapan awal mulai dilakukan dengan mengajukan permohonan izin pelaksanaan penelitian setelah mendapatkan izin dari pihak Rumah Sakit peneliti memulai dengan melaksanakan pengumpulan data ke bagian rekam medis dan ber koordinasi dengan kepala bidang keperawatan dan 
kepala ruangan ICU.

Peneliti menjelaskan kepada para calon responden tentang tujuan, manfaat, dan prosedur pengisian kuesioner. Pasien yang menanda tangani informed consent atau diwakilkan keluarga. Responden diminta untuk mengisi kuesioner yang telah diberikan oleh peneliti. Setelah itu dilakukan pengambilan kultur darah pada pasien yang terpasang CVC selama 48 jam, selanjutnya peneliti menunggu hasil dalam 3 hari. Selanjutnya peneliti mengambil data dengan dari tim PPI rumah sakit.

Instrumen penelitian dalam bentuk kuesioner yang disusun sendiri oleh peneliti yang berpedoman pada tinjauan pustaka. Serta dari data rekam medik pasien yang berupa hasil kultur. Instrument penelitian terdiri dari 3 bagian yaitu: data demografi yang berisi umur, jenis kelamin, agama, latar belakang pendidikan, lama bekerja untuk responden perawat, dan untuk respoden pasien. Kedua tentang pernyataan penerapan bundel IADP, dan Ketiga tentang data adanya infeksi atau tidak infeksi.

Analisa univariat menghasilkan distribusi dan persentase. Analisa bivariat untuk mengetahui adanya hubungan atau korelasi. Uji statistik yang digunakan adalah uji Chi-square.

\section{HASIL DAN PEMBAHASAN}

Analisa Univariat

Data Demografi berdasarkan karakteristik data demografi responden dapat dilihat di Tabel 1.

\begin{tabular}{|c|c|c|}
\hline $\begin{array}{l}\text { Tabel 1. Distribus } \\
\text { Respond } \\
\text { Data Den }\end{array}$ & grafi ${ }^{\text {B }}$ & $\begin{array}{l}\text { ekuensi } \\
\text { sarkan }\end{array}$ \\
\hline Katrakteristik & Jumlah & $\%$ \\
\hline$\overline{\text { Umur }}$ & & \\
\hline $1 \mathrm{bln}-10$ thn & 13 & 40,6 \\
\hline 11 thn -20 thn & 5 & 15,6 \\
\hline 21 thn -40 thn & 2 & 6,3 \\
\hline 41 thn -60 thn & 5 & 15,6 \\
\hline$>60$ thn & 7 & 21,9 \\
\hline Total & 32 & 100 \\
\hline Jenis kelamin & & \\
\hline Laki - laki & 20 & 62,5 \\
\hline Perempuan & 12 & 37,5 \\
\hline Total & 32 & 100 \\
\hline$\overline{\text { Pendidikan }}$ & & \\
\hline Tidak sekolah & 10 & 31,3 \\
\hline SD & 10 & 31,3 \\
\hline SMP & 5 & 15,6 \\
\hline SMA & 6 & 18,8 \\
\hline PT & 1 & 3,1 \\
\hline Total & 32 & 100 \\
\hline$\overline{\text { Pekerjaan }}$ & & \\
\hline Belum bekerja & 18 & 56,3 \\
\hline PNS & 3 & 9,4 \\
\hline Pegawai swasta & 4 & 12,5 \\
\hline Dll & 7 & 21,9 \\
\hline Total & 32 & 100 \\
\hline$\overline{\text { Agama }}$ & & \\
\hline Islam & 17 & 53,1 \\
\hline Kristen & 14 & 43,8 \\
\hline Hindu & 1 & 3,1 \\
\hline Total & 32 & 100 \\
\hline
\end{tabular}

Berdasarkan Tabel 1 dapat dilihat bahwa karakteristik responden berdasarkan umur mayoritas berumur 1 bln sampai 10 tahun sebanyak 13 orang $(40,6 \%)$, berdasarkan jenis kelamin mayoritas laki-laki sebanyak 20 orang 
(62,5\%), berdasarkan pendidikan mayoritas tidak sekolah sebanyak 10 orang $(31,3 \%)$, dan SD sebanyak 10 orang $(31,3 \%)$, berdasarkan pekerjaan responden mayoritas tidak bekerja sebanyak 18 orang $(56,3 \%)$, berdasarkan agama mayoritas Islam sebanyak 17 orang $(53,1 \%)$.

Tabel 2. Distribusi Frekuensi Berdasarkan Perawatan Catether Vena Central (CVC)

\begin{tabular}{lcc}
\hline Perawatan CVC & Jumlah & Persentase (\%) \\
\hline Baik & 28 & 87.5 \\
Cukup baik & 4 & 12.5 \\
\hline \multicolumn{1}{c}{ Total } & 32 & 100 \\
\hline
\end{tabular}

Berdasarkan hasil penelitian pada

Tabel 2, mayoritas perawatan catether vena central (CVC) di ruang ICU adalah baik sebanyak 28 (87.5\%).

Tabel 3. Distribusi Frekuensi Berdasarkan Kejadian Infeksi Aliran Darah Primer (IADP)

\begin{tabular}{ccc}
\hline Kejadian IADP & Jumlah & Persentase (\%) \\
\hline Tidak terjadi IADP & 27 & 84.4 \\
Bias terjadi IADP & 5 & 15.6 \\
\hline Total & 32 & 100 \\
\hline
\end{tabular}

Berdasarkan Tabel 3 dapat dilihat bahwa mayoritas tidak terjadi kejadian IADP sebanyak 27 orang $(84,4 \%)$, dan dapat terjadi IADP hanya 5 orang
$(15,6 \%)$.

\section{Analisis Bivariat}

Hasil penelitian dapat dilihat pada Tabel 4 sebagai berikut:

Tabel 4. Distribusi Responden Berdasarkan Hubungan Perawatan CVC Dengan Terjadinya Infeksi Aliran Darah Primer (IADP)

\begin{tabular}{|c|c|c|c|c|c|c|c|c|}
\hline \multirow{3}{*}{$\begin{array}{c}\text { Perawatan } \\
\text { CVC }\end{array}$} & \multicolumn{6}{|c|}{ Kejadian IADP } & \multirow{3}{*}{$P$} & \multirow{2}{*}{$\mathbf{X}^{2}$} \\
\hline & \multicolumn{2}{|c|}{ Tidak terjadi } & \multicolumn{2}{|c|}{ Terjadi } & \multirow{2}{*}{ Total } & \multirow{2}{*}{$\%$} & & \\
\hline & $f$ & $\%$ & $f$ & $\%$ & & & & \\
\hline$\overline{\text { Baik }}$ & 27 & 84,4 & 1 & 3,1 & 28 & 87.5 & 0,000 & 24,686 \\
\hline Cukup Baik & 0 & 0,0 & 4 & 12,5 & 4 & 12.5 & & \\
\hline Total & 27 & 84,4 & 5 & 15,6 & 32 & 100 & & \\
\hline
\end{tabular}

Berdasarkan Tabel 4, perawatan CVC yang cukup baik dengan tingkat kejadian IADP pada pasien sebanyak 4 orang $(12,5 \%)$. Hasil uji statistik didapat nilai $p$ value $=0.000(<0,05)$ dapat disimpulkan ada hubungan perawatan catether vena central (CVC) dengan terjadinya Infeksi Aliran Darah Primer (IADP). Hasil analisa nilai Chi- square $\mathrm{X}^{2}=24,686$ lebih besar dari $\mathrm{X}^{2}{ }_{2(0,05)}=$ 5,991 maka ada hubungan diantara dua variabel tersebut. 


\section{Pembahasan}

\section{Penerapan Perawatan CVC}

Berdasarkan hasil penelitian, mayoritas perawatan CVC yang dilakukan atau dilaksanakan oleh perawat adalah baik sebanyak 28 perawatan $(87,5 \%)$. Disini peneliti mencoba mengembangkan isi dari bundle IADP itu sendiri, dengan menambahkan beberapa item- item yang ditemukan di lapangan yang terkait dengan perawatannya.

Penelitian Widiastuti dan Wahjuprajitno (2014) ditemukan durasi pemakaian CVC adalah 1.751 hari. Tingkat tertinggi adalah di bangsal neurologi. Durasi CVC yang digunakan, penggunaan nutrisi parenteral, sebagai faktor paling dominan yang mempengaruhi kejadian infeksi pada pasien tersebut.

Perawatan harus sesuai dengan asuhan keperawatan. Kepatuhan tenaga medis khususnya perawat dalam melaksanakan tindakan sesuai SPO sangat penting perannya dalam menekan nilai terjadinya infeksi. Infeksi yang dapat terjadi yaitu infeksi lokal di tempat bekas insersi atau infeksi aliran darah perifer (IADP).

Institute for Healthcare Improvement (2012) menjelaskan lima langkah utama pencegahan CLABSI sebelum insersi CVC yaitu tindakan mencuci tangan, menggunakan alat perlindungan diri, antiseptik kulit dengan clorhexidine gluconate $2 \%$, menghindari lokasi insersi pada daerah femoral, serta melakukan penilaian harian kebutuhan pemakaian akses sentral.

Strategi pencegahan IADP seperti mencuci tangan yang efektif sebelum insersi/menggunakan akses CVC, menggunakan APD, sarung tangan steril, antiseptik, membersihkan hub kateter selama 10 detik sebelum menggunakan, serta penggunaan dressing bertujuan untuk mencegah kontaminasi kuman patogen secara intraluminal.

Adapun hal yang sering terlupakan dalam perawatan yaitu melakukan swab dengan alkohol swab sebelum melakukan injeksi, melakukan spouling menggunakan $\mathrm{NaCl} \quad 0,9 \%$ setelah melakukan injeksi, serta hal yang jarang dilakukan yaitu Segera melepas CVC apabila terdapat tanda-tanda infeksi, karena yang didapat harus dirawat dahulu, sampai menunggu instruksi dokter, jika setelah dirawat ternyata tanda-tanda infeksi masih didapati maka alat baru dilepas.

Hal yang jarang dilakukan bahkan ada tidak pernah yaitu memberikan Heparin sesuai dosis dokter apabila terjadi obstruksi pada line vena kateter. Pemberian heparin dapat menyebabkan gangguan hemorrahagic screening test (HST) yaitu penilaian perdahan, 
khususnya pada pasien anak dan pasien dengan hemodinamik yang tidak stabil. Menggunakan closed sistem (Q-site) juga jarang dilakukan karena ketersediaan alat (Q-site) yang terbatas.

Pada penelitian ini peneliti menemukan hal yang unik, dimana jika terdapat atau ditemukan tanda-tanda infeksi di daerah penusukan atau daerah insersi, seperti kemerahan dan atau pus, kateter tidak langsung dilepas, tetapi dilakukan perawatan terlebih dahulu. Ada beberapa kasus walaupun dengan jumlah yang sangat kecil terbukti berhasil.

Peneliti mendapatkan bahwa banyak pasien anak-anak yang mengalami infeksi, mengingat mereka rentan atau mudah terinfeksi. Hal itu sebabnya petugas medis yang bersinggungan dengan pasien harus menjalankan semua tindakan sesuai dengan SPO yang sudah ada. Banyak kebijakan yang dikeluarkan rumah sakit yang mengacu pada keselamatan pasien (patient safety).

Hubungan Perawatan Catether Vena Central (CVC) pada Pasien Terpasang CVC Terhadap Terjadinya Infeksi Aliran Darah Primer (IADP)

Hasil uji statistik didapat ada hubungan perawatan catether vena central (CVC) Pada pasien terpasang CVC terhadap terjadinya Infeksi Aliran Darah Primer (IADP). Perawatan CVC merupakan salah satu asuhan keperawatan yang diberikan pada pasien terpasang CVC, dimana acuan yang dilakukan harus sesuai dengan bundle IADP, pencegahan infeksi nosokomial salah satunya adalah perawatan yang tepat.

Berdasarkan hasil analisis deskriptif diketahui bahwa perawat di ruang ICU rumah sakit sebagian besar melakukan perawatan dengan baik. Rumah sakit selalu menjaga mutu pelayanan yaitu salah satunya adalah patient safety. Hal itu karena penularan infeksi harus diminimalisir sesuai dengan SPO atau acuan yang telah dibuat.

Berdasarkan karakteristik responden mayoritas berumur 1 bln sampai 10 tahun. Peneliti melakukan penelitian di ruang PICU (Pediatric Intensive Care Unit). Banyaknya terapi atau obat obatan yang diberikan sehingga memerlukan akses vena yang adekuat. Perawatan asuhan keperawatan yang baik harus dilaksanakan dengan pendokumentasian yang benar. Perawatan CVC yang cukup baik dengan tingkat kejadian IADP pada pasien menunjukkan sebanyak 4 orang dimana hasil kulturnya terdapat infeksi dengan CVC yang terpasang lebih dari 7 hari.

Langkah-langkah pencegahan IADP dalam penerapan bundle IADP atau perawatan CVC dapat berbeda antara satu rumah sakit satu dengan yang lain 
tergantung dari kebijakan dari rumah sakit tersebut. Tindakan perawat terkait dengan perawatan tersebut yang dapat disimpulkan perawatan yang cukup baik dapat menimbulkan infeksi, baik infeksi lokal pada daerah insersi seperti kemerahan, berpus, atau basah. Penggunaan transparan dressing dapat membantu dengan jelas saat kita mengobservasi luka insersi. Dimana dressing mengandung clhorhexidine dapat menyerap perdaharan yang terjadi pada luka.

Pada penelitian ini penggunaan dressing transparan cukup baik, walaupun terkadang masih ada yang menggunakan kasa kering dan plester, ini dikarenakan setelah pemasangan CVC sering terjadi perdarahan daerah insersi, sehingga penggunaan transparan dressing kadang tidak digunakan. Setelah insersi, penggantian dressing dilakukan 24- 48 jam setelah insersi.

Perawatan yang tepat menjadi sasaran untuk menekan jumlah kejadian infeksi. Cara untuk meningkatkan kepatuhan tenaga medis pada Central Line Bundle (perawatan CVC), edukasi dan pengawasan secara berkala oleh tim Pengendali dan Pencegahan Infeksi (PPI) rumah sakit tentang IADP sangat diperlukan.

Penelitian ini memilki keterbatasan dalam waktu penelitian dengan sampel yang kecil dibandingkan dengan studi yang telah dilakukan sebelumnya. Penelitian longitudinal dengan jumlah sampel yang besar diharapkan dapat dilakukan untuk meningkatkan diagnosis dan pencegahan IADP di ruang ICU.

\section{KESIMPULAN DAN SARAN}

\section{Kesimpulan}

Perawatan catether vena central (CVC) di ruang ICU adalah mayoritas perawatan baik, dan mayoritas tidak terjadi kejadian IADP.

Hasil uji statistik didapat nilai $p$ value $=0.000 \quad(<0,05)$ maka dapat disimpulkan ada hubungan perawatan catether vena central (CVC) Pada pasien terpasang CVC terhadap terjadinya Infeksi Aliran Darah Primer (IADP).

\section{Saran}

Bagi Responden

Agar dapat menambah pengetahuan dan pengalaman perawat tentang perawatan CVC pada pasien dengan terjadinya Infeksi Aliran Darah Primer.

Bagi Rumah Sakit

Agar dapat memberikan pedoman atau petunjuk bagi perawat di ruang ICU di rumah sakit.

Bagi Peneliti Selanjutnya

Agar menjadi informasi jika ingin melakukan penelitian tentang hubungan perawatan CVC pada pasien dengan terjadinya Infeksi Aliran Darah Primer. 


\section{DAFTAR PUSTAKA}

Agarwal, P., Warner, M. B., Reichner, C., \& Lazarous, D. G. (2014). Marino's the ICU book, 4th edition. Annals of the American Thoracic Society. https://doi.org/10.1513/AnnalsATS.2 01404-164OT

Centers for Disease Control and Prevention. (2016). National and State Associated Infections Progress Report. Centers for Disease Control and Prevention.

Garber, S. J., \& Puopolo, K. M. (2015). Prevention of central line-associated bloodstream infections among infants in the neonatal intensive care unit. NeoReviews.

https://doi.org/10.1542/neo.16-4e211

Institute for Healthcare Improvement. (2012). How-to Guide: Prevent Central LineAssociated Bloodstream Infections (CLABSI). Retrieved from https://www.chpso.org/sites/main/file s/file-

attachments/ihi_howtopreventcentrall ineassociatedbloodstreaminfections.p df

Kementerian Kesehatan RI. (2012). Pedoman teknis bangunan rumah sakit ruang perawatan intensif. Jakarta: Direktorat Bina Pelayanan Penunjang Medik dan Sarana Kesehatan Direktorat Bina Upaya Kesehatan.

Miller, J. (2017). Critical Care Nursing: Diagnosis and Management 8th edition. Critical Care Nurse. https://doi.org/10.4037/ccn2017185

Said, S., Taslim, N. A., \& Bahar, B. (2016). Hubungan IMT dan kadar albumin berhubungan dengan penyembuhan luka. Jurnal Keperawatan Padjadjaran. https://doi.org/10.24198/jkp.v4n1.6

Widiastuti, E. S., \& Wahjuprajitno, B. (2014). Angka kejadian dan faktorfaktor yang mempengaruhi infeksi paska pemasangan kateter Vena Sentral di Rumah Sakit Dr. Soetomo. JAI (Jurnal Anestesiologi Indonesia). https://doi.org/10.14710/jai.v6i1.657

2 